\title{
Erratum to: Retrofitting social housing: reflections by tenants on adopting and living with retrofit technology
}

\author{
Philip Brown • Will Swan • Sharon Chahal
}

Published online: 6 August 2015

(C) Springer Science+Business Media Dordrecht 2015

\section{Erratum to: Energy Efficiency (2014) 7:641-653 \\ DOI 10.1007/s12053-013-9245-3}

The published online paper unfortunately contained an error. The authors would like to add an acknowledgement to the support from EPSRC. This paper was prepared as part of Grant No. EP/I030832/1, Tackling Fuel Poverty: Bridging the divide for low income and vulnerable communities.

The research materials supporting this publication can be accessed by contacting Prof. Philip Brown (p.brown@salford.ac.uk).

The online version of the original article can be found at http:// dx.doi.org/10.1007/s12053-013-9245-3.

\section{P. Brown $(\bowtie)$}

Sustainable Housing \& Urban Studies Unit, University of Salford, Salford M5 4WT, UK

e-mail: p.brown@salford.ac.uk

W. Swan

School of the Built Environment, Joule House, University of Salford, Salford M5 4WT, UK

S. Chahal

Places for People, 18 South Rings Business Park Craven Drive,

Bamber Bridge, Preston PR5 6BZ, UK 